\title{
CURIOSIDADES FREUDIANAS (1931-1969)
}

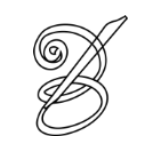

Denise Bottmann ${ }^{1}$

Historiadora e tradutora

dbottmann@gmail.com

Resumo: Este artigo apresenta um levantamento das traduções brasileiras de obras de Freud, desde sua primeira publicação em livro em 1931 até 1969.

Palavras-chave: Sigmund Freud, tradução científica, história da tradução no Brasil

Abstract: This short essay lists Freud's writings translated and published in Brazil, since 1931 to 1969.

Keywords: Sigmund Freud, scientific translation, history of translation in Brazil

I.

Ao que tudo indica, a primeira tradução de Freud que saiu entre nós foi Cinco lições de psicanálise, em 1931.

$\mathrm{Na}$ verdade, houve uma tentativa antes disso: em 1926, o médico Iago Pimentel publicou algumas páginas das Cinco lições, na intenção de traduzi-las na íntegra, diretamente do alemão. Esse excerto saiu no terceiro número d'A Revista, a publicação literária que Carlos Drummond, Pedro Nava e outros haviam criado no ano anterior. Infelizmente, esse terceiro número foi também o derradeiro do periódico belorizontino, e assim Iago Pimentel não levou seu projeto a cabo. A Revista está disponível na Brasiliana USP, em http://www.brasiliana.usp.br/bbd/handle/1918/01956130\#page/1/mode/1up. 

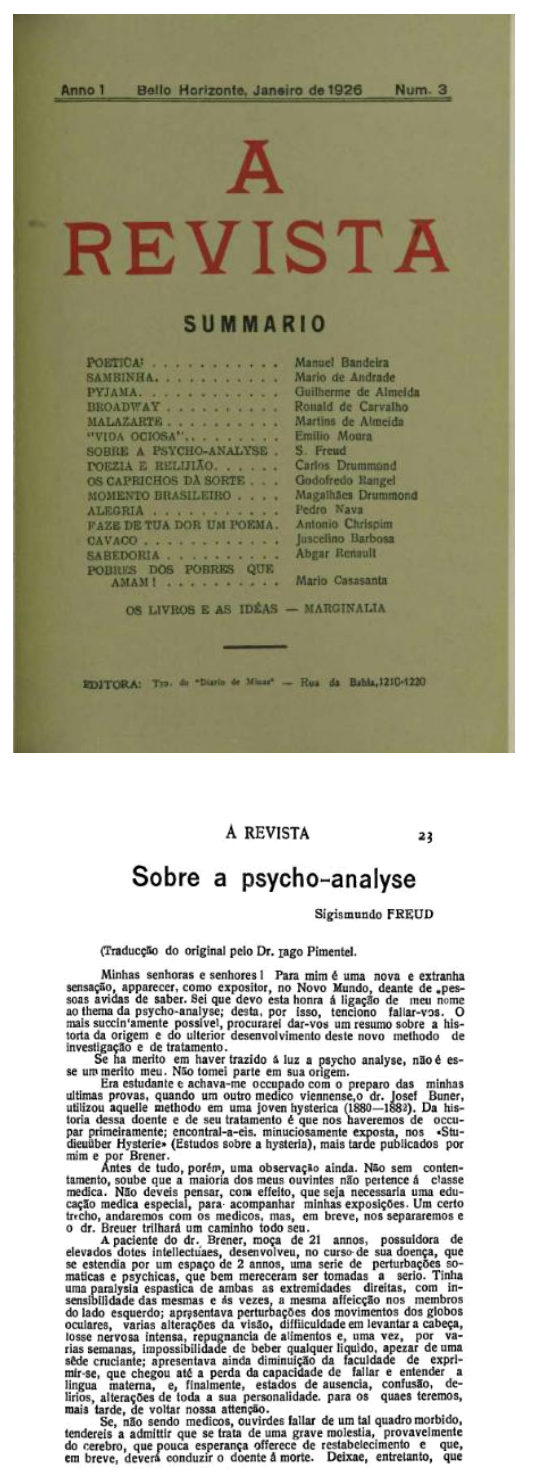

Assim, foi em 1931 que saiu a tradução integral das Cinco lições de psicanálise, feita por Durval Marcondes, tido como o pioneiro da psicanálise no Brasil, e José Barbosa Corrêa, publicada pela Companhia Editora Nacional.

Nessa mesma época, a Sociedade Brasileira de Psicanálise concebe e dá início ao projeto de traduzir as obras de Freud, tarefa realizada (a partir do francês e do espanhol) por médicos integrantes do incipiente movimento psicanalítico brasileiro. A edição fica a cargo da Editora Guanabara (Waissman \& Koogan). Consegui localizar os seguintes títulos lançados no bojo desse projeto:

- $\quad$ 1933, Psychopathologia da vida quotidiana, trad. Elias Davidovitch

- $\quad$ 1934, Introdução à psicanálise, trad. Elias Davidovitch

• $\quad$ 1934, Totem e tabu, "traducção directa do allemão", anônima, revista por J. P. PortoCarrero 
- $\quad$ 1934, O futuro de uma ilusão (Psicanálise das religiões), trad. J. P. Porto-Carrero

- $\quad$ 1934, Psicanálise e psiconeuroses, trad. Odilon Gallotti

- $\quad$ 1934, Técnica psicanalítica e psicologia da angústia, trad. Odilon Gallotti

- $\quad$ 1934, Psicologia da vida erótica, trad. Moysés Gikovate

- $\quad 1935$, Interpretação dos sonhos e outros ensaios, trad. Odilon Gallotti

- $\quad$ 1935, Introdução ao estudo dos sonhos
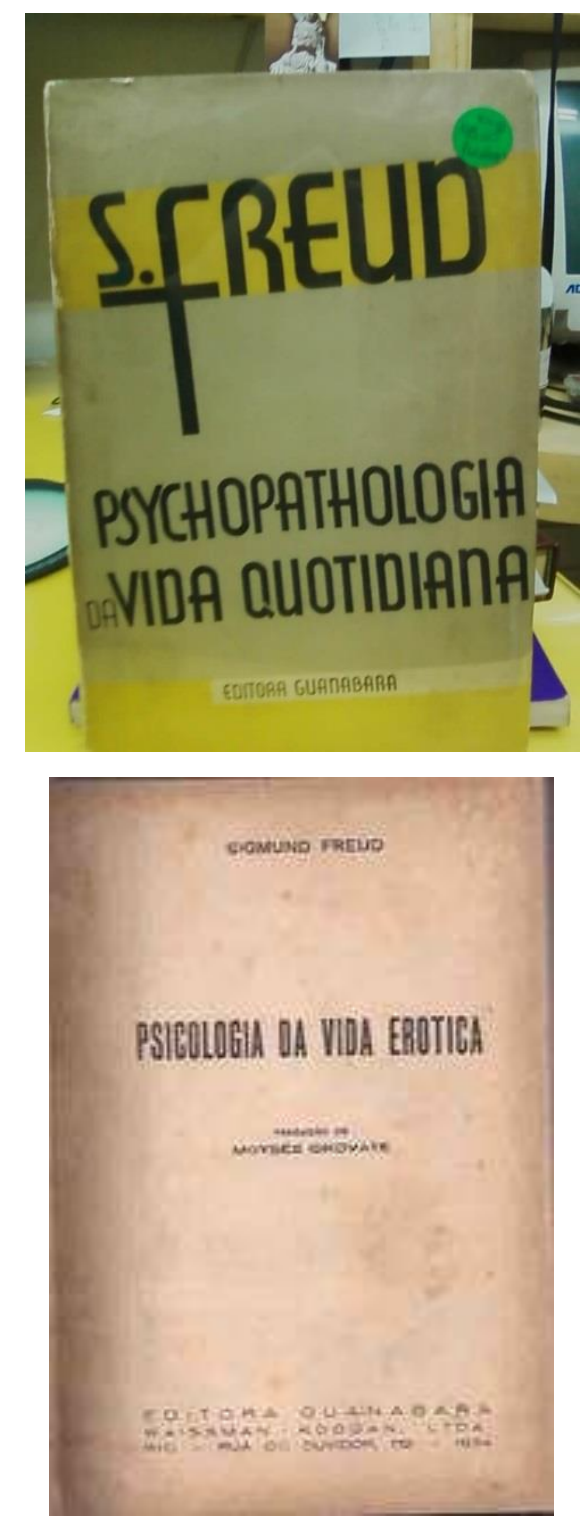


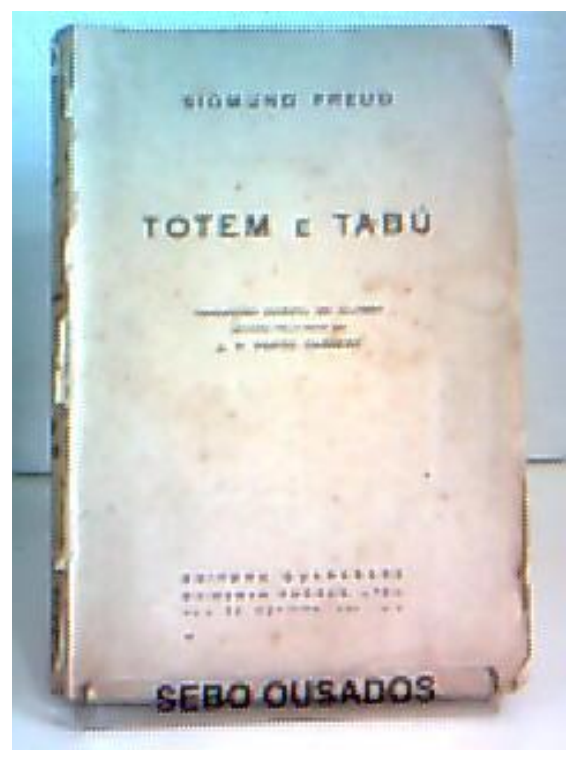

Outros lançamentos de então foram:

- $\quad$ 1934, Observações clínicas, trad. Elias Davidovitch, ed. Atlântida

162 • 1934, Minha vida e a psicanálise, constando apenas "tradução autorizada", ed. Atlântida

- $\quad$ 1934, Pensamentos sobre guerra e morte e O múltiplo interesse da psicanálise, ed. Machado e Ninitch

- $\quad$ 1935, Sexualidade, trad. portuguesa de Osório de Oliveira, ed. Civilização Brasileira

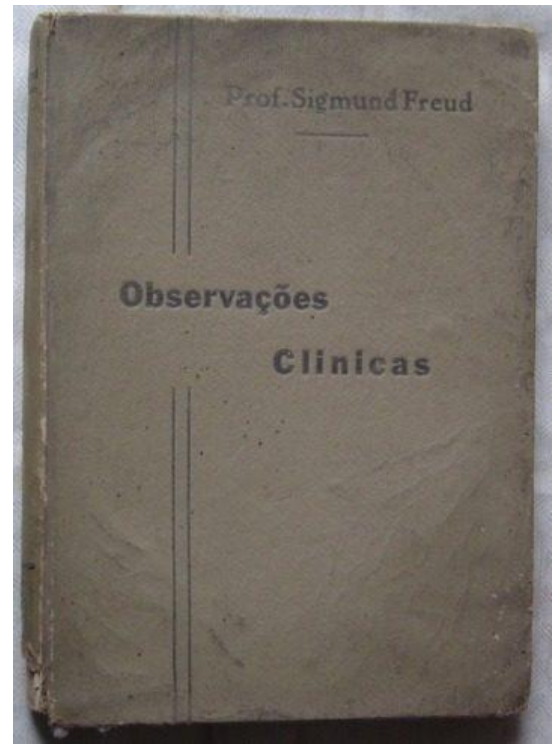



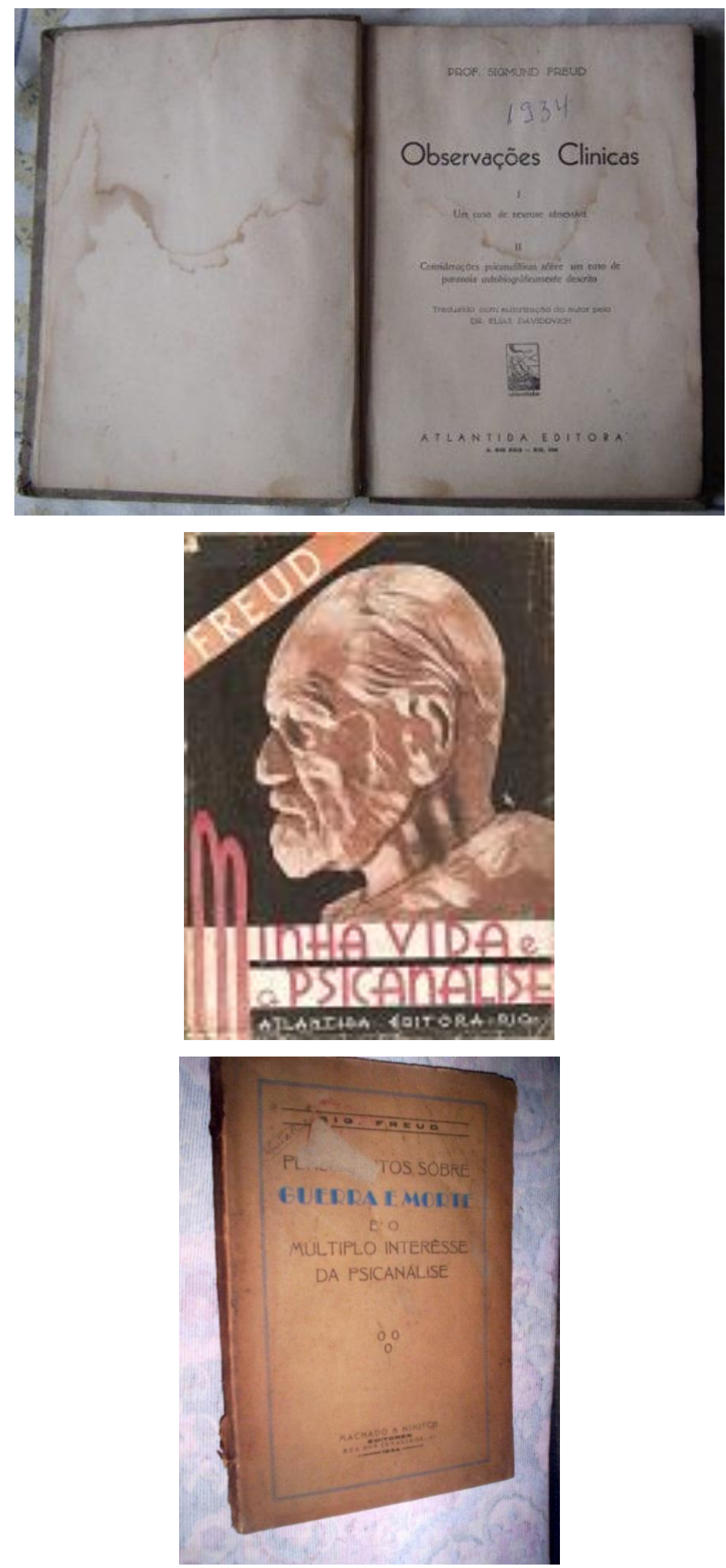


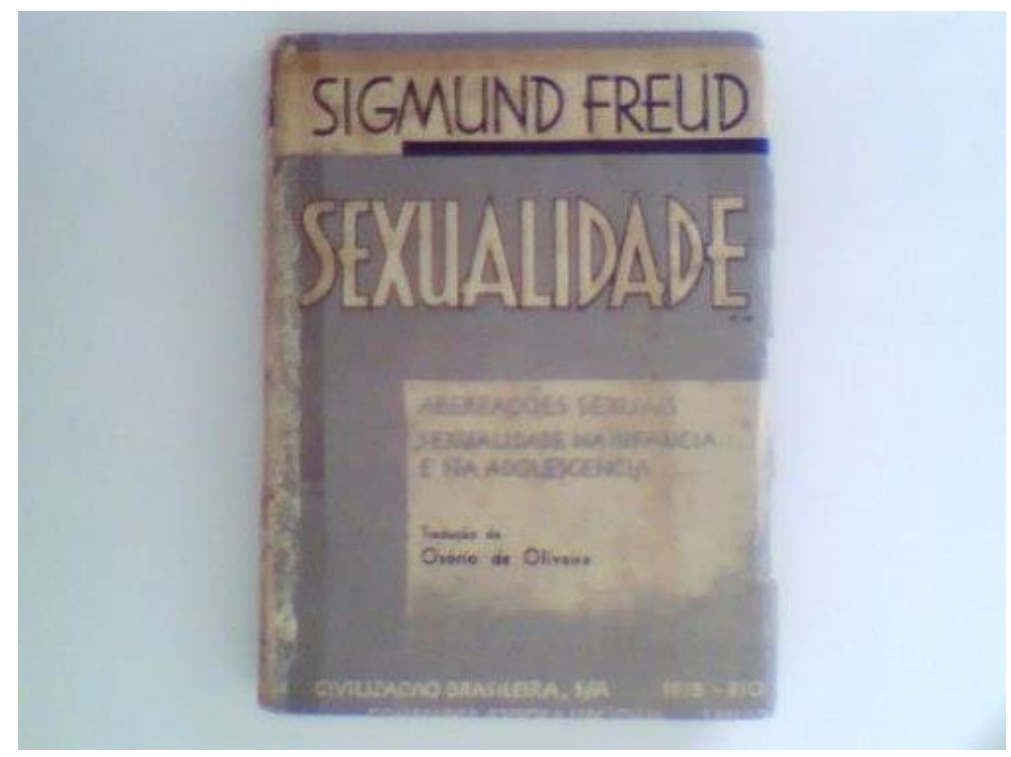

Vale notar que também Anna Freud é publicada no Brasil naquele mesmo período: Introdução à thechnica da analyse infantil sai em 1934, em tradução direta do alemão por Euryalo Canabrava e José Martinho da Rocha, pela editora Livraria Marisa.

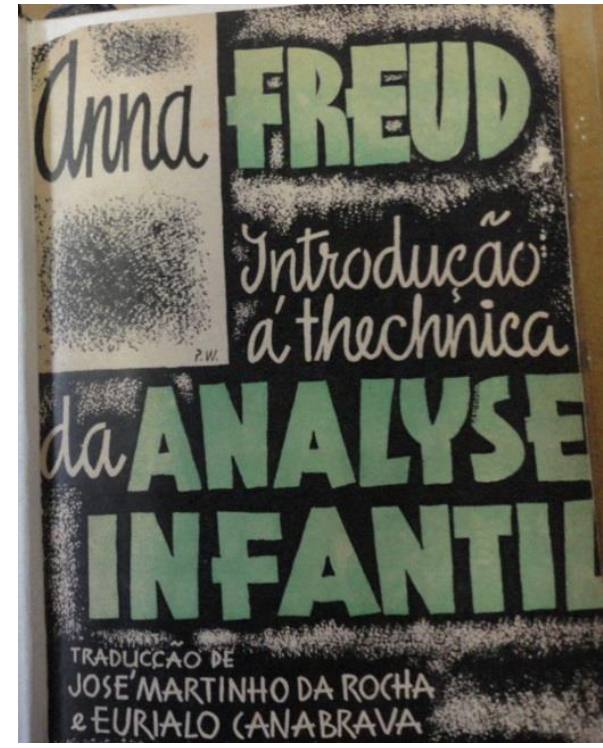




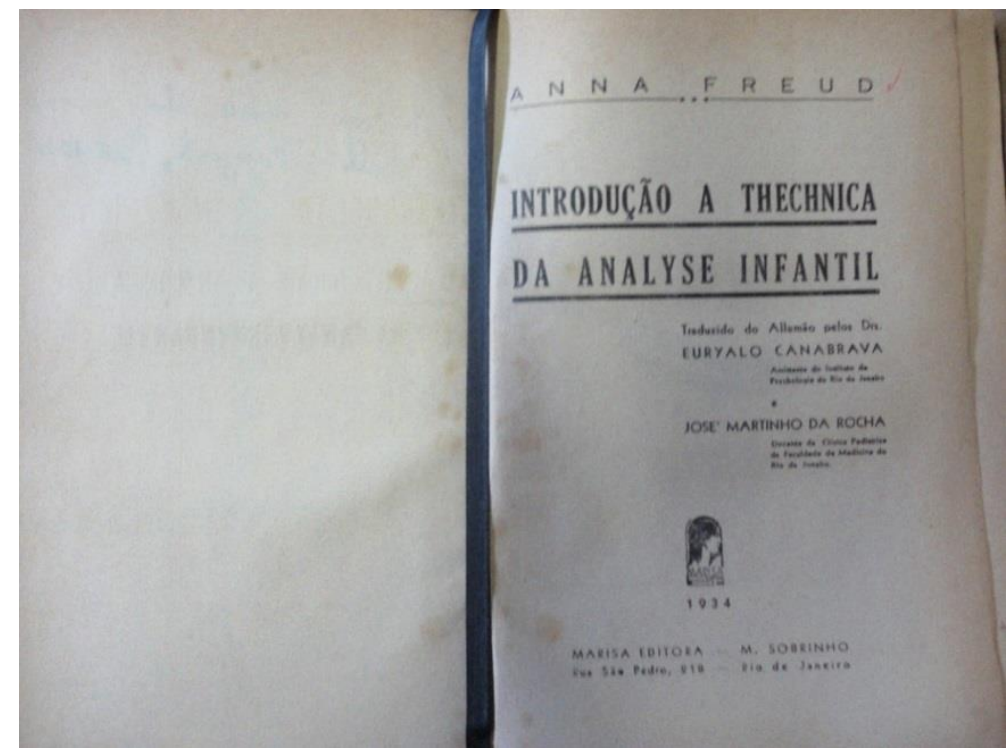

O projeto dos anos 30 da Sociedade Brasileira de Psicanálise para a tradução e publicação das obras completas de Freud, interrompido após 1935, é retomado em 1950 pela Editora Delta, quando dr. Elias Davidovitch encabeça e coordena a coleção.

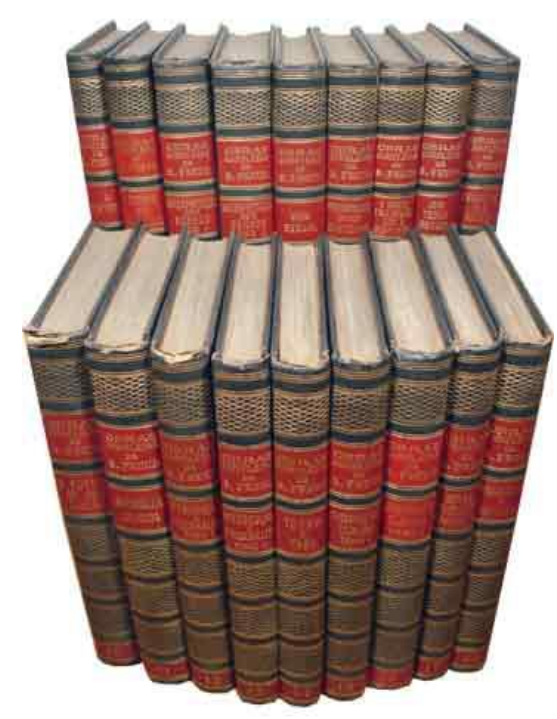

Aqui na edição de 1960

Foi então que a obra freudiana saiu em dezoito volumes, traduzidos alguns do alemão, a maioria do francês e alguns do espanhol, a cargo de nomes de destaque na área psicanalítica. Segue o conteúdo da coleção.

Obras Completas de Sigmund Freud, Delta, 1950:

- $\quad$ volume I - Prefácio. Charcot. A histeria. Trad. C. Magalhães de Freitas. 
- $\quad$ volume II - Primeiras contribuições à teoria das neuroses. Trad. C. Magalhães de Freitas.

- $\quad$ volume III - Interpretação dos sonhos (tomo I). Trad. Odilon Gallotti.

- $\quad$ volume IV - Interpretação dos sonhos (tomo II). Trad. Odilon Gallotti.

- $\quad$ volume V - O delírio e os sonhos na "Gradiva" de W. Jensen. Ensaios sobre a vida sexual e a teoria das neuroses. Trad. Odilon Gallotti e Moysés Gikovate.

- $\quad$ volume VI - Psicopatologia da vida quotidiana. Trad. Elias Davidovitch.

- $\quad$ volume VII - O chiste e sua relação com o inconsciente. Introdução ao narcisismo.

Trad. C. Magalhães de Freitas.

- $\quad$ volume VIII - Uma teoria sexual. Metapsicologia. Mais além do princípio do prazer.

Trad. C. Magalhães de Freitas e Isaac Izecksohn

- $\quad$ volume IX - Psicologia das massas e a análise do eu. Organização genital infantil. $O$ Ego e o Id. Inibição, sintoma e angústia. Trad. Odilon Gallotti e Elias Davidovitch.

- $\quad$ volume X - O futuro de uma ilusão. Esquema da psicanálise. Técnica psicanalítica. Trad. de J. P. Porto-Carrero, Odilon Gallotti e Gladstone Parente

166 volume XI - Psicanálise aplicada. Uma recordação de infância de Leonardo da Vinci. Trad. Elias Davidovitch e Isaac Izecksohn.

- $\quad$ volume XII - Introdução à psicanálise (tomo I). Trad. Elias Davidovitch.

- $\quad$ volume XIII - Introdução à psicanálise (tomo II). Trad. Elias Davidovitch.

- $\quad$ volume XIV - Totem e tabu. Ensaios. Tradução de TT revista por J.-P. Porto-Carrero; Ensaios, trad. Odilon Gallotti e Gladstone Parente. ${ }^{2}$

- $\quad$ volume XV - Observações clínicas (tomo I). Trad. Odilon Gallotti.

- $\quad$ volume XVI - Observações clínicas (tomo II). Trad. Odilon Gallotti.

- $\quad$ volume XVII - Novas contribuições à psicanálise. Múltiplo interesse da psicanálise.

Trad. Gladstone Parente.

- volume XVIII - História do movimento psicanalítico. Autobiografia. Psicanálise e medicina. Índice geral. Trad. Odilon Gallotti, Isaac Izecksohn e Gladstone Parente. 
C H A R C O T

A HISTERIA

Troduça do

Dr. C. MAGALHKES DE FRETAS

EDITORA DELTA S. A.

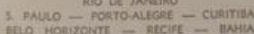

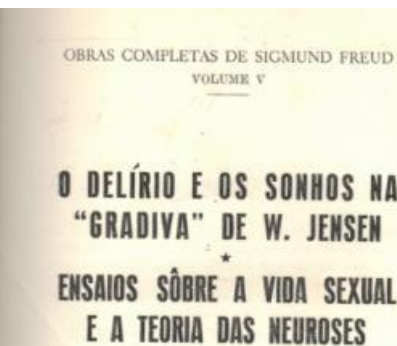

Trodurido pelos Drat

ODILON GALLOTT

EDITORA DELTA S. A.

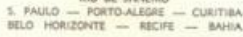

acine - enta

OBRAS COMPLETAS DE SIGMUND FREUD

Voutare vil

O CHISTE E SUA RELAÇĀO

COM $O$ INCONSCIENTE

INTRODUÇÃO AO NARCISISMO

Trodurido pelo
Dr. C. MAGLLHXES DE FREITAS

EDITORA DELTA S. A.

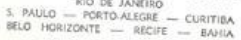


UMA TEORIA SEXUAL

METAPSICOLOGIA

MAIS ALÉM DO PRINCIPIO DO PRAZER

Troduzido pelos Drs.

C. MAGALHAES OE FREITAS
ISAAC IZECKSOHN

EOITORA DELTA S. A.

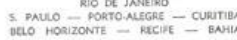

ORRLS COMPLETAS DE SIGMUND FREUD Voutras $x$

\section{OBSERVACÕES CLínicas}

томо I

Por outro lado, interrompido o projeto da Sociedade Brasileira de Psicanálise para a tradução da obra completa de Freud, pela Guanabara (1933-35) e antes de sua retomada em 1950, aparecem nesse ínterim algumas obras de vulgarização. Em 1940, a Livraria Martins publica O pensamento vivo de Freud, de Robert Waelder, uma coletânea de excertos de Freud organizados tematicamente, em tradução de Catarina Baratz Canabrava. 

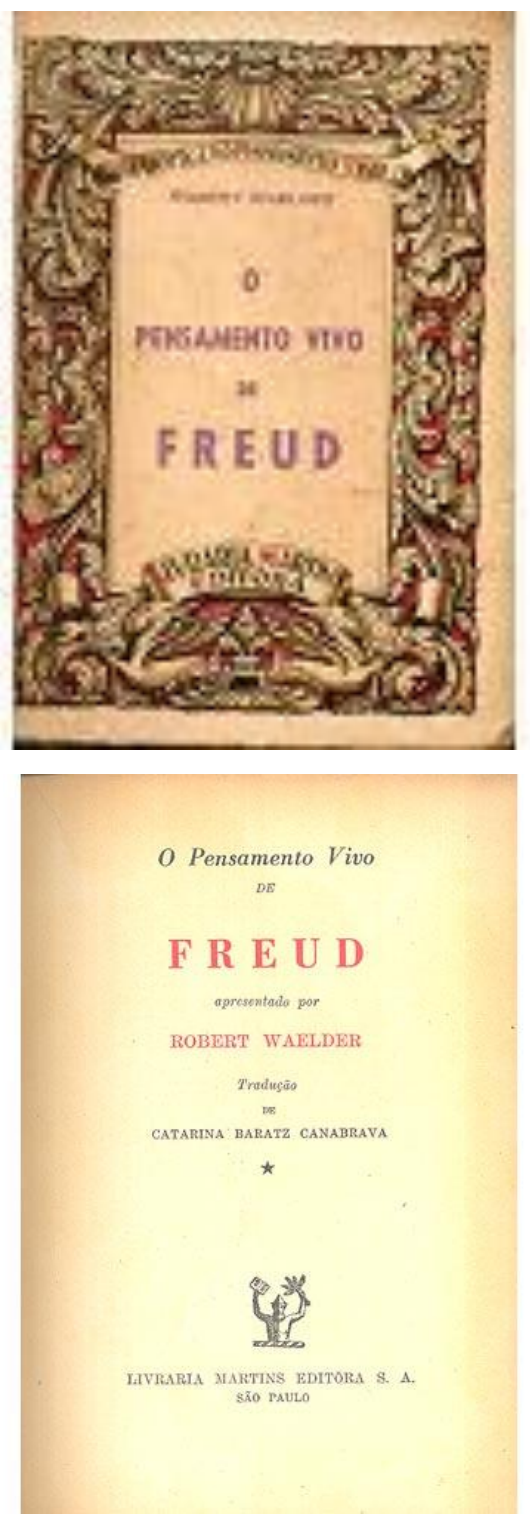

Sobretudo em 1941 e 1942 tem-se um verdadeiro surto de popularização freudiana na Editorial Calvino. Trata-se de uma coleção de doze volumes de divulgação chamada "Freud ao alcance de todos", a cargo de "Dr. J. Gomez Nerea", pseudônimo do peruano Alberto Hidalgo, poeta e romancista vanguardista radicado na Argentina, amigo de Borges, Huidobro e Macedónio Fernández. 


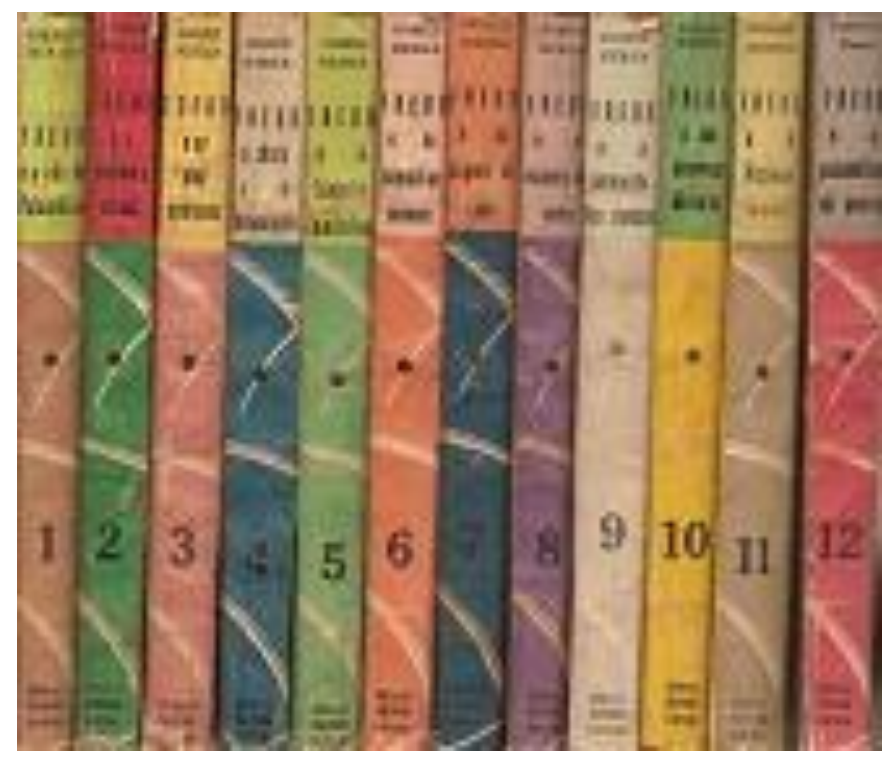

A referida coleção consiste nos seguintes volumes:

1. Freud e o abc da psicanálise (trad. N. Jonas Hersen)

2. Freud e o problema sexual

3. $\quad$ Freud e os atos maníacos (trad. Galvão de Queiroz)

170 4. Freud o chiste e o inconsciente (trad. Francisco de Oliveira e Silva)

5. Freud e a histeria feminina

6. $\quad$ Freud e as anomalias sexuais (trad. Gastão Pereira da Silva)

7. $\quad$ Freud e as origens do sexo (trad. Abguar Bastos)

8. Freud e os mistérios do sonho

9. $\quad$ Freud e a perversão das massas (trad. Abguar Bastos)

10. Freud e seu processo de curar (trad. Francisco de Oliveira e Silva)

11. Freud e a higiene sexual

12. Freud e a psicanálise de guerra (trad. Gastão Pereira da Silva) 

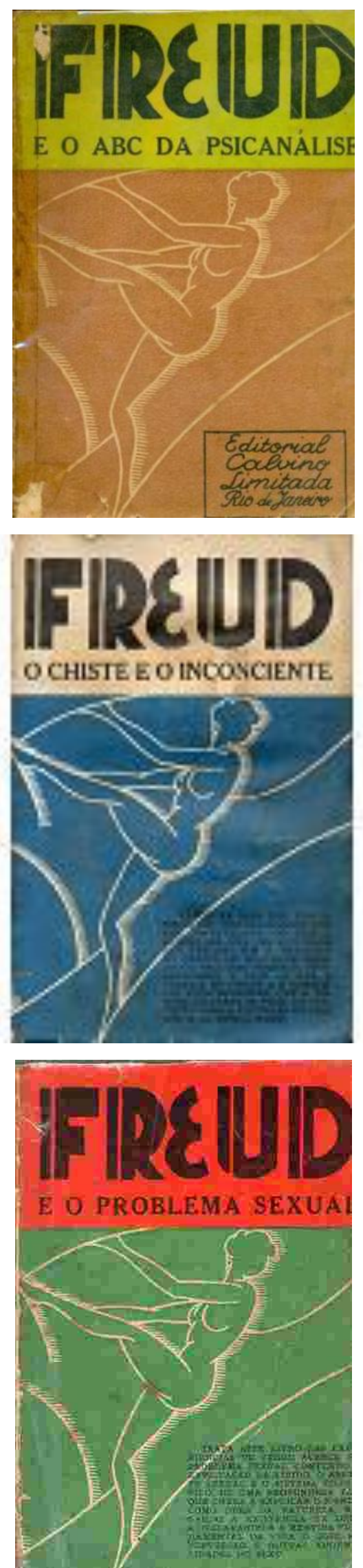


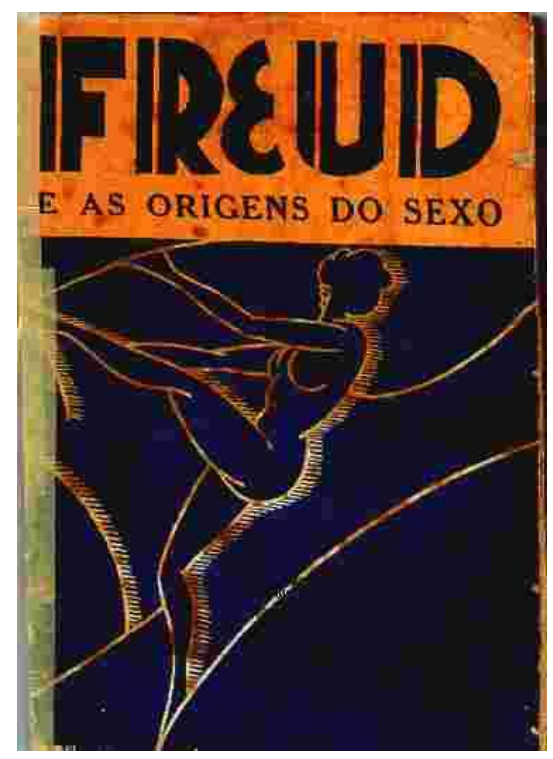

Como Elias Davidovitch já traduzira algumas coisas para a Calvino nos anos 30 (a saber, $O$ tyrano de Dostoiévski e $O$ príncipe de Maquiavel), não parece totalmente impossível que tenha sido ele a sugerir essa coleção à editora.

II.

Tal é, em suma, a situação de Freud traduzido em livro no Brasil até 1969, ano em que a Imago Editora começa a publicar suas obras completas em 24 volumes, basicamente a partir do inglês, seguindo a standard edition de James Strachey, com vários tradutores. No interregno desde as obras completas pela Delta em 1950 até as obras completas pela Imago a partir de 1969, o único outro lançamento que localizei, ${ }^{3}$ foi Psicopatologia da vida cotidiana em tradução de Álvaro Cabral, em 1964, pela editora Zahar.

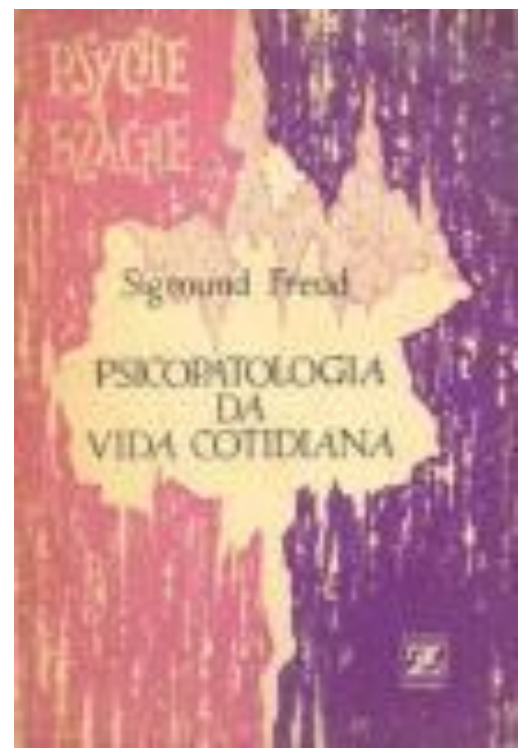


A partir de 1969, com a publicação da chamada "edição standard brasileira", creio que a fortuna de Freud no Brasil é bastante conhecida. Para anos mais recentes, acrescentem-se as iniciativas da editora Companhia das Letras, com Paulo César Souza, e da editora L\&PM, com vários tradutores, em traduções feitas diretamente do alemão.

Fontes: Fundação Biblioteca Nacional, Portal Estante Virtual, acervos de bibliotecas universitárias e de associações psicanalíticas.

\footnotetext{
${ }^{1}$ Currículo lattes - Denise Guimarães Bottman. Disponível em: http://lattes.cnpq.br/4979718236781288.

${ }^{2}$ Agradeço a Saulo von Randow Jr. pelos dados de tradução deste volume.

${ }^{3}$ Uma excentricidade sem data, que calculo por volta de 1967-69, é um livro de nome Psicanálise dos tempos neuróticos, atribuído a Freud. No entanto, diz a apresentação: "Procuramos fazer, neste trabalho, a síntese do pensamento de Freud, em relação à psicanálise de guerra, extraída do seu curiosíssimo trabalho 'Zeitgemaesses ueber Krieg und Tod', que se estendem, depois, através das publicações feitas pela 'Internationaler PsychoAnalitischer Verlag', e de uma conferência realizada em Budapeste, em 1918, também publicada por aquela sociedade".
} 